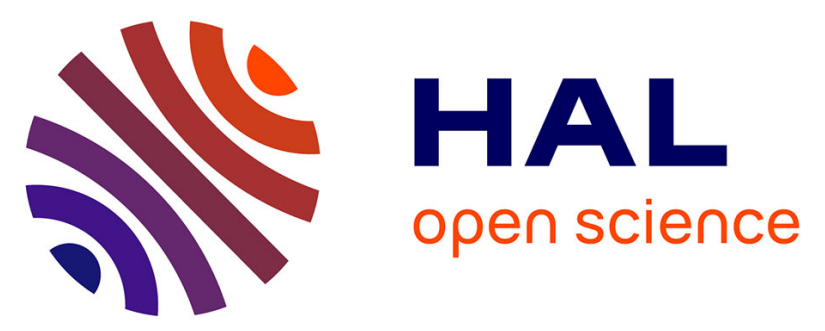

\title{
Complete and rapid reversal of the body color pattern in juveniles of the convict surgeonfish Acanthurus triostegus at Moorea Island (French Polynesia)
}

Marc Besson, Pauline Salis, Vincent Laudet, David Lecchini

\section{- To cite this version:}

Marc Besson, Pauline Salis, Vincent Laudet, David Lecchini. Complete and rapid reversal of the body color pattern in juveniles of the convict surgeonfish Acanthurus triostegus at Moorea Island (French Polynesia). Coral Reefs, 2017, 10.1007/s00338-017-1631-4 . hal-01628304

\section{HAL Id: hal-01628304 https://hal.sorbonne-universite.fr/hal-01628304}

Submitted on 3 Nov 2017

HAL is a multi-disciplinary open access archive for the deposit and dissemination of scientific research documents, whether they are published or not. The documents may come from teaching and research institutions in France or abroad, or from public or private research centers.
L'archive ouverte pluridisciplinaire HAL, est destinée au dépôt et à la diffusion de documents scientifiques de niveau recherche, publiés ou non, émanant des établissements d'enseignement et de recherche français ou étrangers, des laboratoires publics ou privés. 


\title{
Complete and rapid reversal of the body color pattern in juveniles of the convict surgeonfish Acanthurus triostegus at Moorea Island (French Polynesia)
}

\author{
Marc Besson $^{1,2} \cdot$ Pauline Salis $^{2} \cdot$ Vincent $_{\text {Laudet }^{2}} \cdot$ David Lecchini $^{1,3}$
}

\begin{abstract}
Color polymorphism is widespread in animals and can be associated with temporary adjustments to environmental variables (phenotypic plasticity). In teleost fishes, one of the most remarkable examples of color plasticity is background adaptation in flatfishes. However, such rapid and complete changes in body color and pattern remain relatively unreported in other species. The convict surgeonfish Acanthurus triostegus is a gregarious species whose body color pattern consists of black vertical bars on a whitish body. Here, we describe an entirely reverse body color pattern (white vertical bars on a blackish body) that we observed in some A. triostegus juveniles in a nursery area at Moorea Island, French Polynesia. In aquaria, we determined that change from one color pattern to the other is rapid, reversible, and corresponds to phenotypic plasticity associated with aggressive behavior.
\end{abstract}

Marc Besson and Pauline Salis: equal first authors.

Vincent Laudet and David Lecchini: equal last authors.

Marc Besson

marc.besson@ens-lyon.org

1 EPHE-UPVD-CNRS, USR3278-CRIOBE, PSL ResearchUniversity, BP 1013, 98729 Papetoai, Moorea, French Polynesia

2 CNRS-UMR7232-OOB, UPMC, 1 Avenue Pierre Fabre, 66650 Banyuls-sur-Mer, France

3 Laboratoire d'Excellence "CORAIL", BP 1013, 98729 Papetoai, Moorea, French Polynesia
Keywords Color pattern · Phenotypic plasticity · Fish behavior - Acanthurus triostegus

\section{Introduction}

The occurrence of two or more distinct and genetically influenced color morphs within a single interbreeding population, i.e., color polymorphism, is widespread across the animal kingdom (Endler 1980; Gray and McKinnon 2007). Individuals can also adjust body colors and patterns in response to environmental factors such as habitat background, temperature, food availability, population density and level of predation risk (Leimar 2007). This environmentally influenced color plasticity within individuals of the same genotype is highly adaptive when facing changing and selective environments (Gray and McKinnon 2007).

In teleost fishes, phenotypic plasticity in color patterns is well exemplified by background adaptation (camouflage) in flatfishes (Ramachandran et al. 1996; Höglund et al. 2002; Kelman et al. 2006). Body color and pattern adjustments can also be associated with temporary social status (Beeching 1995; Höglund et al. 2002), sexual display (Kodric-Brown 1998; Rhodes and Schlupp 2012) or response to a predation risk (Fuller and Berglund 1996). Changes in body colors and patterns are regulated by a variety of genetic, endocrine and cellular processes such as distribution, morphology and density of pigment organelles and chromatophores (Fujii and Novales 1969; Sugimoto 2002; Miller et al. 2007). These changes can be fixed or reversible and can occur within a few weeks or a few seconds, representing long-term or rapid adaptations to the environment (Sugimoto 2002; Sköld et al. 2013). For example, the dusky dottyback (Pseudochromis fuscus) can 
change its body coloration from yellow to brown and vice versa within 2 weeks, depending on habitat and prey availability (Messmer et al. 2005; Cortesi et al. 2015), while the paradise whiptail (Pentapodus paradiseus) can switch its head and body reflective stripes from blue to red in less than one second, presumably for communication (Mäthger et al. 2003).

Apart from the complex body color and pattern changes observed during camouflage in flatfishes (Ramachandran et al. 1996) and agonistic interactions in cichlid fishes (Beeching 1995), rapid changes (within a few seconds) are generally discrete (e.g., apparition or change in color of a stripe) and relatively unreported in other fish species (Fujii et al. 1989; Mäthger et al. 2003; Rhodes and Schlupp 2012; Watson et al. 2014). While long-term (within a few days or weeks) color and pattern changes have been described for coral reef fishes during ontogeny (Frédérich et al. 2010), sexual maturation (Kodric-Brown 1998) and mimicry strategies in adults (Cortesi et al. 2015), rapid and complete pattern changes remain relatively little explored (Fujii et al. 1989; Mäthger et al. 2003; Watson et al. 2014), particularly in juveniles, for which most studies have focused on slower ontogenetic changes (McCormick et al. 2002).

The convict surgeonfish Acanthurus triostegus is a common herbivorous reef fish in the Indo-Pacific region (Randall 1961). Adults are encountered around reef patches close to the barrier reef where they live in large aggregations mostly feeding on turf algae (Randall 1961). The color pattern of reef-associated juveniles and adults consists of black vertical bars on a whitish body (referred to here as 'classical color pattern,' CP; Fig. 1a; Randall 1961; Frédérich et al. 2012). Here, in a nursery area of Moorea Island (Lecchini et al. 2005), in French Polynesia, we observed some A. triostegus juveniles exhibiting a complete reversal of their color pattern: white vertical bars on a blackish body (referred here as 'reversal of the color pattern,' RP; Fig. 1b) and chasing their conspecifics. The aim of this study was to better characterize the RP and to determine whether it is associated with behavioral and/or developmental characteristics, and corresponds to phenotypic plasticity. We collected large cohorts $(n>50)$ of reef-naïve A. triostegus larvae while they colonized the reef at Moorea Island, and raised them in aquaria until the appearance of the RP. We demonstrated that the CP-RP change is rapid and reversible, and that this phenotypic plasticity is associated with aggressive behavior.

\section{Materials and methods}

\section{Fish sampling and raising}

Fish larvae were collected nightly in March 2015 using a crest net on the northeast coast of Moorea Island, French Polynesia $\left(17^{\circ} 29^{\prime} 52.19^{\prime \prime} \mathrm{S}, 149^{\circ} 45^{\prime} 13.55^{\prime \prime} \mathrm{W}\right)$, close to the nursery area where RP juveniles were observed. The crest net had a mesh size of $1 \mathrm{~mm}$ and was equipped with a rectangular mouth (width: $1.5 \mathrm{~m}$, height: $1 \mathrm{~m}$ ) oriented perpendicular to the water flow. The crest net retains all settlement-stage (reef-naïve) larvae as they move over the
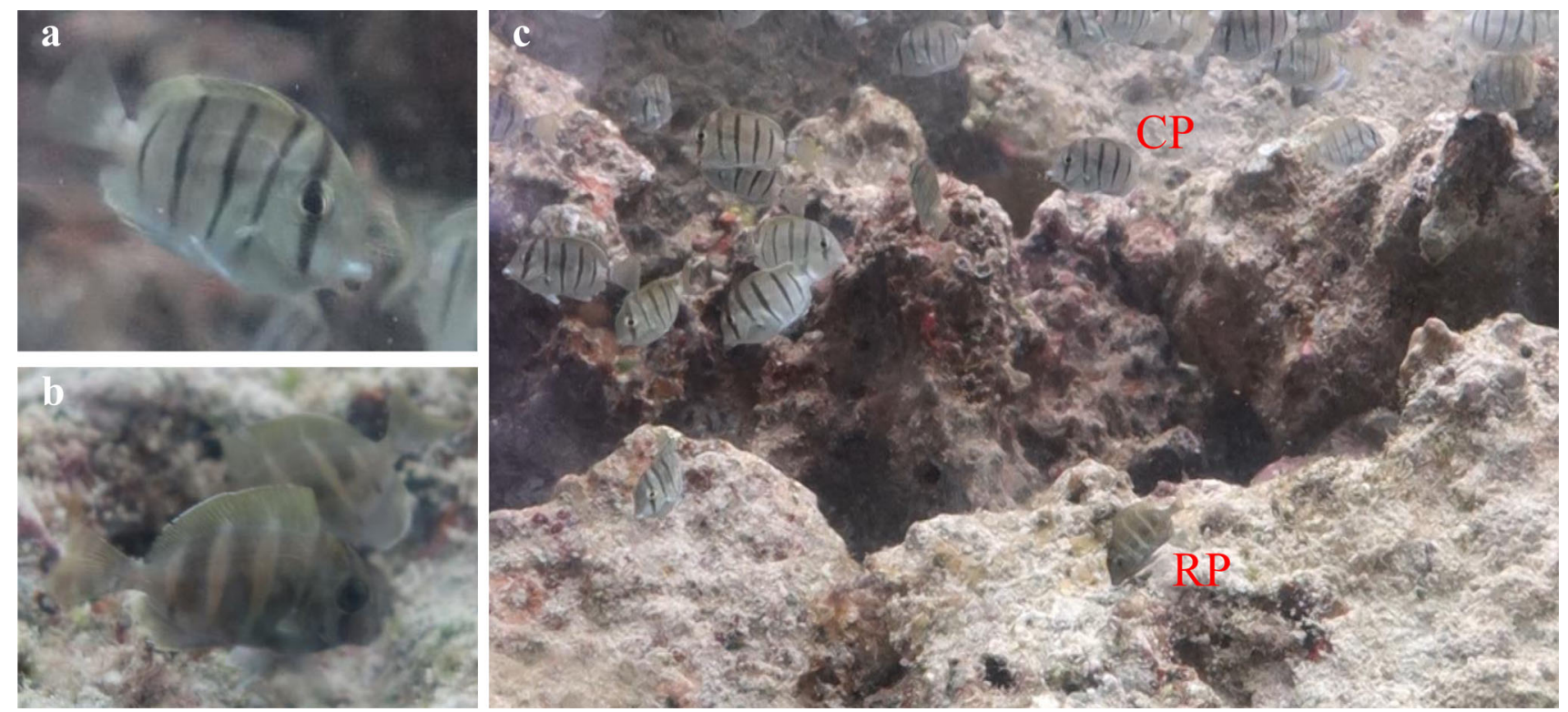

Fig. 1 Body color patterns and community organization of Acanthurus triostegus juveniles. a 'Classical color pattern' (CP) of a convict tang juvenile at day 7 post-settlement. $b$ 'Reversal of the color pattern' (RP) of two juveniles also erecting their dorsal fin. c Shoal and community organization of CP (top) and RP (bottom) juveniles 
reef crest and enter the net (Dufour and Galzin 1993). As larval fish recruit to reefs at night, the net was set up at $1900 \mathrm{~h}$ and larvae were collected at $0200 \mathrm{~h}$ the following day. Three large cohorts of A. triostegus larvae were collected consecutively ( $n=53,60$ and 69). After removal from the crest net, individuals were transferred to the CRIOBE research station where they were maintained, with only their respective larval cohort, in a 200-L aquarium in an open water circuit. Water temperature was maintained at $28.5^{\circ} \mathrm{C}$, under a $12: 12 \mathrm{LD}$ cycle $(0600 \mathrm{~h}$ onset to $1800 \mathrm{~h}$ offset), and fish were fed turf algae using live rocks and rubble that were changed daily. Fish were released at day 11 post-settlement in the nursery area close to their collection site.

\section{Juvenile body color pattern, developmental stage and behavior}

Every day from capture to release, the entire fish cohort was observed at 0800,1200 and $1600 \mathrm{~h}$ for $30 \mathrm{~min}$, to assess the color pattern of each fish. Pigmentation pattern prevalence in each cohort (i.e., percentage of CP and RP fish in each of the three cohorts) was assessed when RP juveniles were first observed, at day 7 post-settlement (Fig. 2a). To ensure that CP $(n=14)$ and RP $(n=10)$ fish were at the same developmental stage, individual body depth (body height divided by standard length) was recorded, as it is a good indicator of post-settlement development in A. triostegus (McCormick 1999; McCormick et al. 2002). To ensure that aquaria did not impair fish development, we also measured individual body depth in day 7 post-settlement juveniles that were raised in smaller groups of 20 individuals in in situ cages in the nursery area close to the crest net. Body depth comparisons were made using ANOVA followed by Tukey's post hoc tests after verification of data normality and homoscedasticity. To compare the behaviors of the two color patterns, aggressiveness of $\mathrm{CP}(n=24)$ and $\mathrm{RP}(n=24)$ fish was assessed at day 7 post-settlement using camera records (mean $\pm \mathrm{SE}$ duration of $5.0 \pm 0.9 \mathrm{~s}$ for $\mathrm{CP}$ and $6.3 \pm 1.7 \mathrm{~s}$ for $\mathrm{RP}$ ). The percentage of time each unique individual spent with the dorsal fin erected was assessed from the camera records (Fig. 2c). A high percentage of time with the dorsal fin erected was considered as aggressive behavior (Brawn 1960; Gerlai 2003).

\section{Results and discussion}

After observation of A. triostegus juveniles exhibiting a RP in a dense nursery area of Moorea Island, we confirmed, in aquaria, the occurrence of the RP in three separate groups of juveniles ( $n=53,60,69$, respectively) originating from three larval cohorts that we collected at settlement. At day 7 post-settlement, $13.3 \pm 2.5 \%$ of A. triostegus juveniles had changed color pattern from CP to RP (Fig. 1a, b; Fig. 2a). This change occurred in $1.33 \pm 0.64 \mathrm{~s}$ (Electronic supplementary material, ESM, Video S1) and lasted until fish release (day 11 post-settlement). The change was also rapidly reversible, as disturbing the fish by introducing a net in the aquarium lead RP juveniles to turn into CP and to mix with the CP shoal. This confirms that the CP-RP transition corresponds to a reversible, complete and rapid color pattern change in juveniles. The RP has never been encountered in adults (Randall 1961; McCormick 1999).

There was no difference in body depth between RP and $\mathrm{CP}$ juveniles raised in aquaria and $\mathrm{CP}$ juveniles raised in in situ cages in a lagoon nursery area (ANOVA, $n=43$,
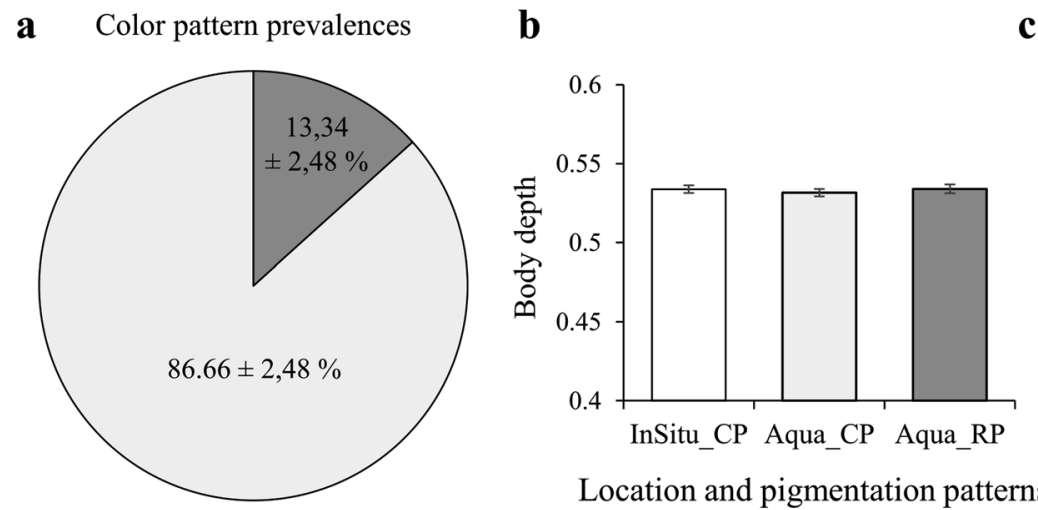

Location and pigmentation patterns

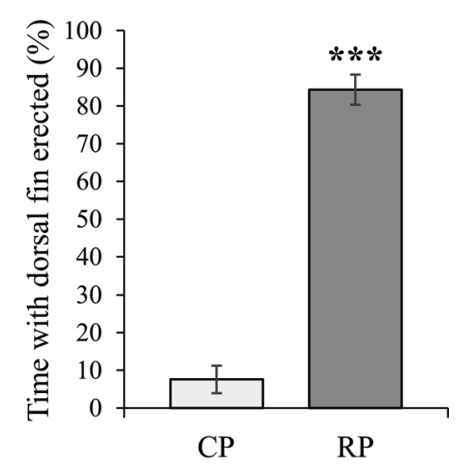

Pigmentation patterns
Fig. 2 Color pattern prevalence, ontogenetic stage and behavior of $\mathrm{CP}$ and RP juveniles at day 7 post-settlement. a Color pattern prevalence of classical color pattern (CP, light gray) and reversal color pattern (RP, dark gray) juveniles at day 7 post-settlement in $n=3$ juvenile cohorts held in aquaria. b Body depth (body height/standard length) of CP individuals held in situ in lagoon cages
(InSitu_CP, white bar, $n=20$ ) or held in aquarium (Aqua_CP, $n=14$ ) and of RP individuals held in aquarium (Aqua_RP, $n=10$ ). c Percentage of time spent with the dorsal fin erected in CP (light gray, $n=24$ ) and RP (dark gray, $n=24$ ) juveniles held in aquaria. Errors bars indicate standard errors. $* * * p$ value $<0.001$ (Wilcoxon) 
$F=0.063, p=0.939$; Fig. 2b). This suggests that these two patterns are not related to an ontogenetic difference. RP was also different from the stressed/nocturnal pigmentation pattern, which consists of the $\mathrm{CP}$ with black rectangles between each bar (ESM Fig. S1). RP was associated with aggressive behavior, with RP juveniles chasing their conspecifics (ESM Video S2). This was exemplified by the significant difference between $\mathrm{CP}$ and RP juveniles in the percentage of time spent with the dorsal fin erected $(7.6 \pm 3.6 \%$ vs. $84.3 \pm 4.0 \%$, respectively; Wilcoxon rank-sum test, $n=48, W=569, p<0.001$; Fig. 2c), which illustrates the aggressive behavior of RP individuals (Brawn 1960; Gerlai 2003). Consequently, the presence of the RP resulted in a newly organized fish community, with RP juveniles defending their territory, while $\mathrm{CP}$ juveniles swam or foraged in groups above the guarded areas (Fig. 1c; ESM Video S3). Therefore, the CP to RP transition in A. triostegus juveniles is a rare observation of a rapid and complete reversal of the body color pattern that is not associated with camouflage or mimicry (Ramachandran et al. 1996; Höglund et al. 2002; Kelman et al. 2006; Sköld et al. 2013; Watson et al. 2014). In fact, this behavior is reminiscent of the cichlid fish Astronotus ocellatus, where agonistic interactions between males can lead to rapid change in color pattern (darkening of the body color and appearance of white vertical bars) in individuals defeated in combat, with opposite behavioral consequences (i.e., inhibition of aggression; Beeching 1995).

At the cellular level, color and pattern changes can be divided in two categories: morphological and physiological color changes (MCC and PCC; Fujii and Novales 1969; Leclercq et al. 2010). MCC often result from long-term changes in the distribution, morphology and density of chromatophores (pigment cells), while PCC originate from rapid motile movements of pigment organelles (e.g., melanosomes) within the chromatophores (Sugimoto 2002; Leclercq et al. 2010; Sköld et al. 2013). Here, the rapidity of the CP-RP change suggests that this results from PCC and that condensation/dispersion of melanosome in the melanophores may be responsible for the rapid and reversible black/white color reversal (Zhu and Thomas 1997). However, a cellular study of this process is required to confirm this hypothesis.

This study demonstrates phenotypic plasticity in juveniles of A. triostegus, revealing an ability to switch from one color pattern to its complete opposite within a few seconds. While $\mathrm{CP}$ and RP fish also exhibited distinct behaviors, individuals turning from $\mathrm{CP}$ to RP were not predictable and did not show any prior detectable phenotypic difference. Renewing rubble (with fresh turf algae) twice a day and diminishing the number of juveniles in the aquarium delayed and even prevented the appearance of the RP (Besson pers. obs.). Further investigation is therefore required to test whether this phenotypic plasticity is juvenile specific and only appears in conditions of intense foraging competition, and whether the RP aggressive and solitary behavior is the result of an adaptive strategy to force some individuals to quit the cohort in situations of low resource availability.

Acknowledgements We would like to thank $\mathrm{H}$. Jacob and A. Mignucci for their help in the field, as well as B. Frédérich and T. Lorin for their helpful comments which greatly improved this manuscript.

\section{References}

Beeching SC (1995) Colour pattern and inhibition of aggression in the cichlid fish Astronotus ocellatus. J Fish Biol 47:50-58

Brawn VM (1960) Aggressive behaviour in the cod (Gadus callarias L.). Behaviour 18:107-147

Cortesi F, Feeney WE, Ferrari MCO, Waldie PA, Phillips GAC, McClure EC, Sköld HN, Salzburger W, Marshall NJ, Cheney KL (2015) Phenotypic plasticity confers multiple fitness benefits to a mimic. Curr Biol 25:949-954

Dufour V, Galzin R (1993) Colonization patterns of reef fish larvae to the lagoon at Moorea Island, French Polynesia. Mar Ecol Prog Ser 102:143-152

Endler JA (1980) Natural selection on color patterns in Poecilia reticulata. Evolution (N Y) 34:76-91

Frédérich B, Colleye O, Lepoint G, Lecchini D (2012) Mismatch between shape changes and ecological shifts during the postsettlement growth of the surgeonfish, Acanthurus triostegus. Front Zool 9:8

Frédérich B, Mills SC, Denoël M, Parmentier E, Brié C, Santos R, Waqalevu VP, Lecchini D (2010) Colour differentiation in a coral reef fish throughout ontogeny: habitat background and flexibility. Aquat Biol 9:271-277

Fujii R, Novales RR (1969) Cellular aspects of the control of color changes. Am Zool 9:453-463

Fujii R, Kasukawa H, Miyaji K, Oshima N (1989) Mechanisms of skin coloration and its changes in the blue-green damselfish, Chromis viridis: physiology. Zoolog Sci 6:477-486

Fuller R, Berglund A (1996) Behavioral responses of a sex-role reversed pipefish to a gradient of perceived predation risk. Behav Ecol 7:69-75

Gerlai R (2003) Zebra fish: an uncharted behavior genetic model. Behav Genet 33:461-468

Gray SM, McKinnon JS (2007) Linking color polymorphism maintenance and speciation. Trends Ecol Evol 22:71-79

Höglund E, Balm PHM, Winberg S (2002) Behavioural and neuroendocrine effects of environmental background colour and social interaction in Arctic charr (Salvelinus alpinus). J Exp Biol 205:2535-2543

Kelman EJ, Tiptus P, Osorio D (2006) Juvenile plaice (Pleuronectes platessa) produce camouflage by flexibly combining two separate patterns. J Exp Biol 209:3288-3292

Kodric-Brown A (1998) Sexual dichromatism and temporary color changes in the reproduction of fishes. Am Zool 38:70-81

Lecchini D, Shima JS, Banaigs B, Galzin R (2005) Larval sensory abilities and mechanisms of habitat selection of a coral reef fish during settlement. Oecologia 143:326-334

Leclercq E, Taylor JF, Migaud H (2010) Morphological skin colour changes in teleosts. Fish Fish 11:159-193 
Leimar O (2007) Environmental and genetic cues in the evolution of phenotypic polymorphism. Evol Ecol 23:125-135

Mäthger LM, Land MF, Siebeck UE, Marshall NJ (2003) Rapid colour changes in multilayer reflecting stripes in the paradise whiptail, Pentapodus paradiseus. J Exp Biol 206:3607-3613

McCormick MI (1999) Delayed metamorphosis of a tropical reef fish (Acanthurus triostegus): a field experiment. Mar Ecol Prog Ser 176:25-38

McCormick MI, Makey LJ, Dufour V (2002) Comparative study of metamorphosis in tropical reef fishes. Mar Biol 141:841-853

Messmer V, Jones GP, Van Herwerden L, Munday PL (2005) Genetic and ecological characterisation of colour dimorphism in a coral reef fish. Environ Biol Fishes 74:175-183

Miller CT, Beleza S, Pollen AA, Schluter D, Kittles RA, Shriver MD, Kingsley DM (2007) cis-Regulatory changes in Kit ligand expression and parallel evolution of pigmentation in sticklebacks and humans. Cell 131:1179-1189

Ramachandran VS, Tyler CW, Gregory RL, Rogers-Ramachandran D, Duensing S, Pillsbury C, Ramachandran C (1996) Rapid adaptive camouflage in tropical flounders. Nature 379:815-818
Randall JE (1961) A contribution to the biology of the convict surgeonfish of the Hawaiian Islands, Acanthurus triostegus sandvicensis. Pacific Science 15:215-272

Rhodes SB, Schlupp I (2012) Rapid and socially induced change of a badge of status. J Fish Biol 80:722-727

Sköld HN, Aspengren S, Wallin M (2013) Rapid color change in fish and amphibians-function, regulation, and emerging applications. Pigment Cell Melanoma Res 26:29-38

Sugimoto M (2002) Morphological color changes in fish: regulation of pigment cell density and morphology. Microsc Res Tech 58:496-503

Watson AC, Siemann LA, Hanlon RT (2014) Dynamic camouflage by Nassau groupers Epinephelus striatus on a Caribbean coral reef. J Fish Biol 85:1634-1649

Zhu Y, Thomas P (1997) Effects of somatolactin on melanosome aggregation in the melanophores of red drum (Sciaenops ocellatus) scales. Gen Comp Endocrinol 105:127-133 